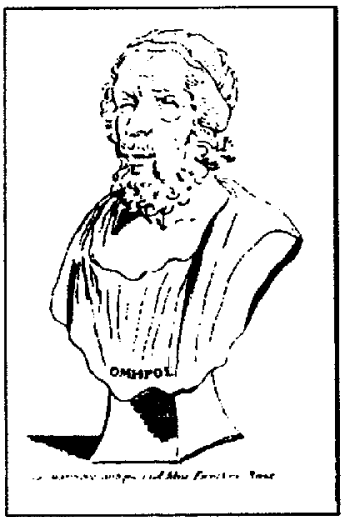

GAIA

Revue interdisciplinaire sur la Grèce archaïque

Numéro 7 / 2003

ERGA

Université Stendhal-Grenoble 3 


\title{
Towards a Thematic Analysis of the Homeric Poems
}

\author{
Alberto Camerotto \\ Università Ca' Foscari, Venezia
}

The epic singers of archaic Greece told the deeds of the heroes and composed and performed their songs in epe in front of the audience by means of their traditional art, or more precisely, of the peculiar instruments of a long and rich tradition. The events of the heroic saga, which we call, with the epic formula, $\kappa \lambda \dot{\varepsilon} \alpha \dot{\alpha} v \delta \rho \hat{v} v$, as well as the plots of the tales, the oî $\mu \alpha$, were traditional. As instruments of tradition we have learned to appreciate the epic diction, the formular language and the formulaic techniques used by the rhapsodes to compose while performing. Another instrument that the singer used in composing and that we can try to identify in the heroic epic texts, are the traditional thematic structures. After the pioneering work of Walter Arend (1933) on the typical scenes (reviewed by Milman Parry, 1936), it was Albert Bates Lord who particularly dealt with this subject and described oral composition in terms of composition by theme, thanks to his experience in comparative field in Bosnia ${ }^{1}$. With regard to the heroic epic poetry of archaic Greece, we can believe that the performance would be carried out - following a selected oime and with the aid of the formular diction - through a sequence of themes and motifs, making it an easier task for the singer.

So far scholars have produced many studies on thematic composition and thematic structures in Homeric poems, but we still don't have a systematic and complete thematic analysis of the whole texts. As soon as we begin such an analysis, we are faced with a question regarding both terminology and concept, because in our studies we have no univocal definition of the thematic elements making up the text. Later, we will try to suggest a working definition of theme and motif, and we'll give two examples of text with themes and motifs, according to the prospects of

1. In part. see Lord $1951 ; 1960,68-98$. 


\section{GAIA 7}

this analysis, but for the moment let us deal with the beginning of the Iliad. Once we have become acquainted with the distinctive features of epic poetry, immediately we perceive, together with the formularity, that the structure of the narration is divided into well defined thematic units, more or less extended. If we compare these scenes, as we shall call them for the time being, with similar scenes in epic poems, even a long way from each other within the same poem or belonging to different poems, we soon realize there are similarities between the narrative schemes and in the use of diction.

Since Arend's work, the identification of typical scenes has become an important prospect for analysis, because it enables us to see and verify connections between formulaic diction and narrative structures, and to identify the schemes or the patterns of oral composition, as in the considerable work by Bernard Fenik, Typical Battle Scenes in the Iliad (1968). But the analysis of typical scenes also involves some problems. We stress the patterns and the formularity of the texts, but in a compositional view we seem to lose the unity of the narrative action as it was thought by the singer. In the work by Arend we perceive the typical features of singular scenes, but they seem formulaic fragments which the poet inserts in a text that is a continuum.

We will now consider the beginning of the Iliad, following the suggestion of Mark Edwards. In his essay « Convention and individuality in Iliad $1^{2} \gg$, Edwards gives us a way for solution, when he analyzes the narrative structure and identifies the type-scenes of the first book of the poem, which cover uninterruptedly the whole text. We will quote here his definition of type-scene, which he proposes in another important essay on these topics, «Homer and Oral Tradition: The Type-Scene ${ }^{3} »$. It will be useful to our work, because it is similar to our definition of theme: «A type-scene may be regarded as a recurrent block of narrative with an identifiable structure» (285) and «The whole of Homeric narrative can be analyzed into type-scenes ${ }^{4} \gg(287)$. But we have to observe that in Edwards' work the perception of unity of the narrative action is still fragmentary. When he analyzes the assembly of the Achaeans in A 54-307, he identifies three type-scenes, Summoning of the Assembly (A 5456), Assembly (A 57-305a), and Dismissal of the Assembly (305b-307). Then, inside the Assembly, he identifies three other type-scenes, Achilleus' $\mu \varepsilon \rho \mu \eta \operatorname{li}^{\prime} \iota v$ (A 188-194a), Athena's Divine Visitation (A 194b-222), and Nestor's Mediation (A 247-304).

2. Edwards 1980, 4-28.

3. Edwards 1992, 285-287. Cf. 1975, 51-72.

4. Cf. Nagler 1974, 81 «it now seems equally plausible that all narrative episodes are equally type scenes, if one means by this term that they are realizations of poetically significant motifs $\gg$. 
Now we must consider that certainly this narrative action is unitary in terms of theme and composition. In this prospect, it does not begin with A 54, but with the transitional line that summarizes the preceeding

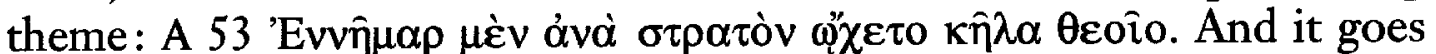
on with the general representation of Achilleus' summoning of the

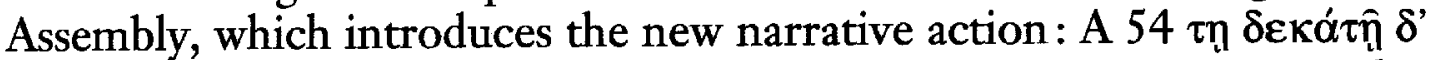

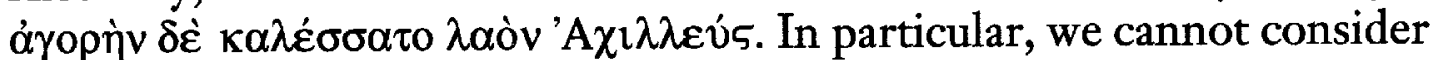
the Summoning and the Dismissal as separate units, since they represent the natural and traditional frame of this type of narrative action. Indeed, these two sections show a higher formular density, as it frequently happens for the beginning and the end of a theme, or of a motif. The Summoning and the Dismissal are components of the Assembly, that is integrated motifs making up the theme. Inside the Assembly, in the same way, Achilleus' pondering and Nestor's mediation are not independent scenes, but integrated motifs of the Assembly, too. We can define as an independent unit only the Divine Visitation of Athena (A 194b-222) ${ }^{5}$, quite similar to many other Divine Visitations in the Epos, on the basis of narrative patterns and diction. It constitutes a separate action in the Assembly. It is a recognizably different theme and has a well distinct beginning and ending, which are marked by two motifs, the arrival (A

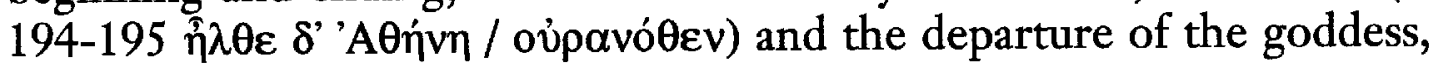
the new subject of the narrative action (A 221-222 ì $\delta^{\prime}$ Ov้ $\lambda v \mu \pi$ ov $\delta \dot{\varepsilon} \beta \varepsilon$ -

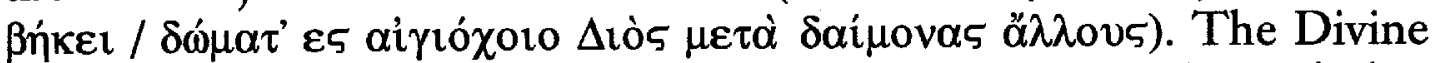
Visitation is made up of a conventional sequence of typical motifs that we can easily recognize because of the frequency of the theme, and it represents a turning-point in the events of the first Assembly of the Iliad, when they are going towards an unexpected outcome. It turns Achilleus towards the menis, that is the argument of the song and the main thread of the Iliad. Therefore, we must consider the intervention of Athena as a new and distinct thematic development within the Assembly. As it happens in battles, the events are getting to a critical situation out of the plot or out of the oime, but the divine intervention corrects them in the expected way ${ }^{6}$. Then, the Assembly resumes its course exactly in the moment when Athena goes away, and Achilleus comes back to insult Agamemnon in front of the Achaeans, with the indication of the new

5. As a part of the new theme, we can consider the transition that precedes the arrival of Athena and recapitulates the pondering action of Achilleus, when he draws the sword:

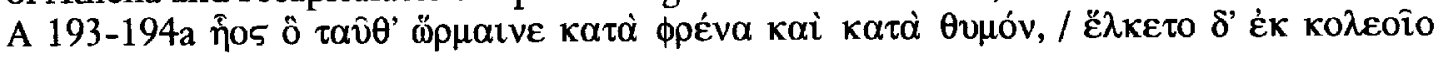

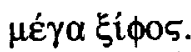

6. See de Jong 1987, 68-81; Morrison 1992, 61-71 «The poet uses this reversal passage abruptly to return the story to its expected - that is, its traditional - path» (62); $1997,285$. 


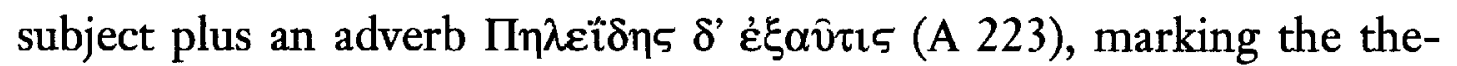
matic transition.

On the one hand this example can give us a concrete idea of what we call a theme, on the other it reveals some of the difficulties we find in the thematic analysis of epic poems. Now, we will try to formulate our working definition of theme and motif.

In the heroic epic poetry, essentially a narrative poetry, the theme is a unit of meaning, which introduces a fundamental action into the tale, causing the development of the events ${ }^{7}$. We can identify as themes, for example, the Assembly (Agora), the Battle (Macbe), the Duel (Monomachia), the Intervention of a god (Enteuxis), the Sacrifice (Thysia), the Hospitality (Xenia), the Inspection of the army (Epipolesis), but we do not consider as themes the scenes of departure and arrival, the preparation of the meal, the arming, because they are subsidiary actions and components inside the theme. So, we observe that the concept of type-scene sometimes coincides with the theme, sometimes with the motif. This alternation depends on the dynamics of composition, because a theme as the Intervention of a god can be reduced to a motif, that is to the simple indication of helping, without other typical motifs of the thematic sequence. In only one hemistich Apollon can save Hektor (H 272 iòv $\delta$ '

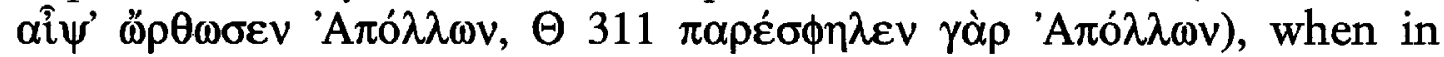
other occurrences we have a larger and complex thematic development of the same action, as in O 220-262.

In the opposite direction, a motif as killing an enemy can be reduced to the simple verb or only to the name of the victim, as an iterated motif in the Battle and particularly in an androktasia, but when it is associated to a larger sequence of subsidiary motifs, it acquires the thematic autonomy and the relief of a Monomachia, or Duel.

The theme is composed by a discrete action with a beginning and an end well identified on the basis of the leading actor, a single character or a group, who is the principal protagonist, and on the basis of the kind of action, of the structure and the formulaic language. The end of a theme and the beginning of the following one are generally marked by transitional lines, often formulaic lines, which sum up the precedent events, or are underlined by adverbs or by chronological indications. The theme is an articulated unit, composed by a sequence of motifs, or smaller units of meaning. The length of a theme is variable, depending on the number

7. See Lord 1938, 440 «a subiect unit, a group of ideas, regularly employed by a singer, not merely in any given poem, but in the poetry as a whole»; 1951, 73 «a recurrent element of narration or description in traditional oral poetry»; 1960, 68 «the groups of ideas regularly used in telling a tale in the formulaic style of traditional song». Cf. Cantilena 1997, 145-146. 
and the articulation of the motifs and on the richness of the ornamental elements.

The motif is the smallest unit of meaning that we identify in our analysis and it is a component of the theme, that is to say motifs make up the sequence of the smallest narrative elements, which build the development of the theme. As Albert B. Lord said, «although he [the singer] thinks of the theme as a unit, it can be broken down into smaller parts: the receipt of the letter, the summoning of the council, and so forth. Yet these are subsidiary to the larger theme ${ }^{8} \gg$.

The motif is generally made up by a simple action and we can identify it by the presence of a verb and on the basis of its meaning. For example, the motif of the hero (or god) who is pondering about an action is identifiable on the basis of the verb $\mu \varepsilon \rho \mu \eta \rho i \zeta \varepsilon ı v$, inside less or more complex

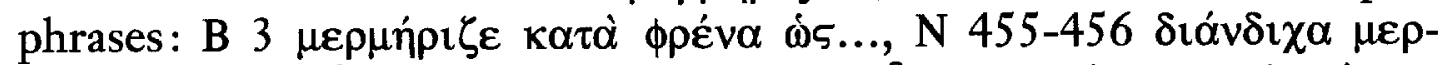

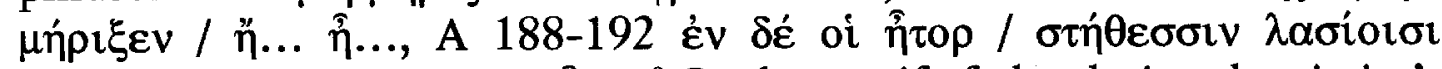
$\delta \iota^{\prime} v \delta \imath \chi \alpha \mu \varepsilon \rho \mu \eta \dot{p} \rho \imath \varepsilon v, / \hat{\eta} \ldots . . \hat{\eta} \varepsilon . .{ }^{9}$ Or the motif of plundering the victim's

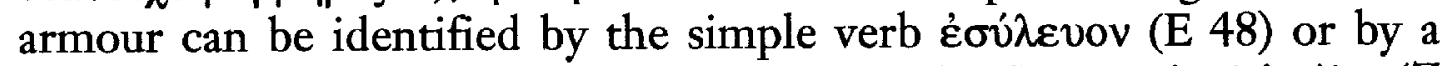

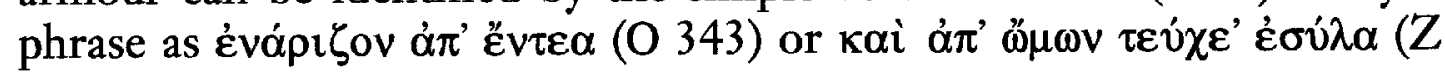
28) ${ }^{10}$.

The length of a motif can be reduced to a single verb (plus a grammatical subject, if there is one) or to a phrase, but it can be expanded to more phrases or more lines, when it is composed by a certain number of ideas or actions regularly associated with the same motif, or when it is amplified by ornamental elements, which do not constitute an independent development of the same action.

In this compositional freedom of contraction and expansion, the motif of the arming can be reduced to a hemistich, as for Menelaos $\mathrm{H}$

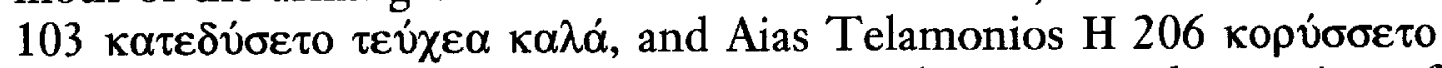
vต́po $\pi \mathrm{r} \chi \alpha \lambda \kappa \hat{\varphi}$, it can be extended to a few lines, as in the arming of Teukros (O 478-482), or it can consist of a large and detailed description as in the famous arming scenes of Agamemnon ( $\Lambda$ 15-55), Patroklos ( $\Pi$ 130-154), and Achilleus (T 364-424). In the duel between Paris and Menelaos, to make another example, for the arming of the Troian hero we have eleven lines ( $\Gamma 328-338$ ), while for the Achaean champion, the

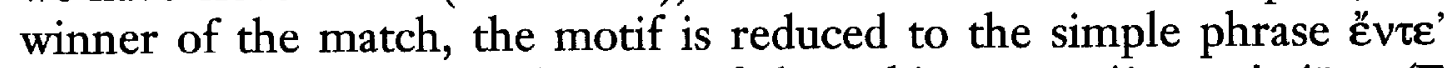

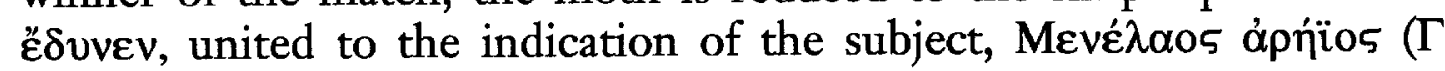
$339)$.

8. Lord 1960, 71.

9. On this motif see Arend 1933, 106-115; Patzer 1972, 26-40; Fenik 1978, 68-90.

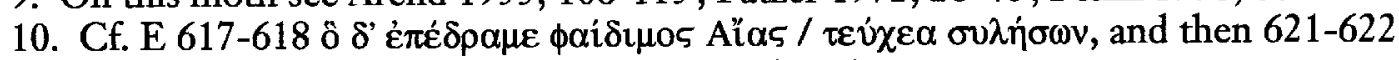

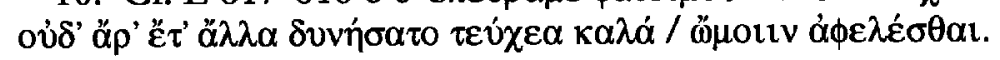


So, nor do we consider the similes as distinct motifs, because they always illustrate and ornament the motif, or the action, and they are integrated in it, as the simile of a lion killing a bull ( $\Pi$ 487-489) and the simile of wrestling between a lion and a boar ( $\Pi$ 823-826) are an expansion of the motif «killing an enemy» in the theme of the Monomachia.

The main function of themes and motifs, as we have said, is a matter of composition. Following the oime, the singer proceeds in his composition, using these units in sequence, with the same freedom with which he uses the formular diction and for the same requirements of oral composition. Themes and motifs are conventional and traditional. Repetition inside the same poem and in other poems of the rhapsodic tradition is the main evidence of the conventionality and of the function of themes and motifs as tools of oral composition itself.

Which concrete objectives do we set ourselves in this work?

First, we need a vertical analysis of the Homeric poems, allowing us to seek and follow the thematic development of the composition and to verify its peculiar dynamics.

Then, with the aid of information technology for research, we can carry out a horizontal analysis of themes and motifs, that is a virtual and simultaneous catalogue for a synoptic vision of all the single themes and motifs in their textual application.

Our last object is to obtain an instrument allowing us to match the results of thematic analysis with the results of the formular analysis, which has been produced by C.O. Pavese and F. Boschetti ${ }^{11}$.

Now, we wish to suggest two brief samples of thematic analysis ${ }^{12}$.

\section{E $1-58$}

\section{Enteuxis}

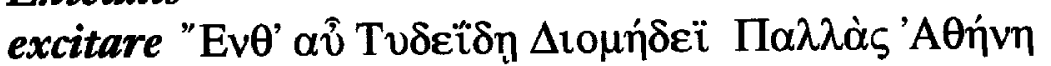

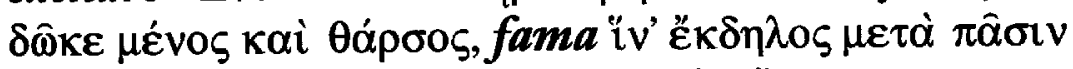

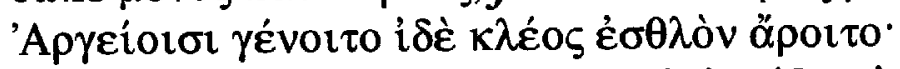

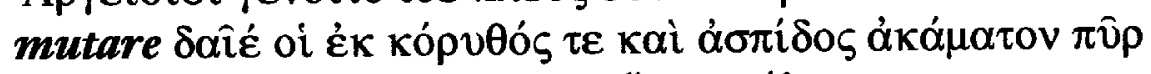

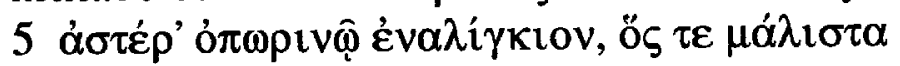

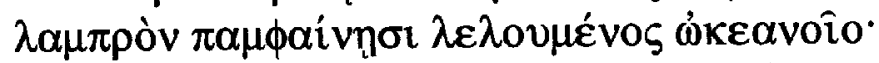

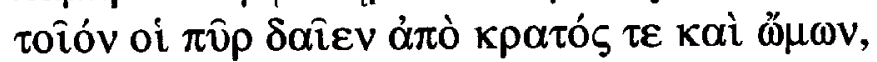

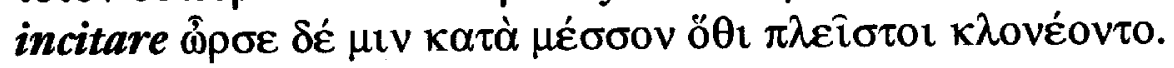

11. Pavese-Boschetti 2003.

12. The themes are identified by Greek terms with capital letter, e.g. Monomacbia (Duel), the motifs by Latin terms, e.g. necare (killing an enemy), all in italics. 


\section{Monomacbia}

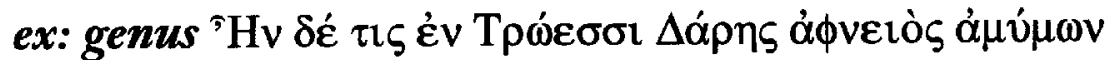

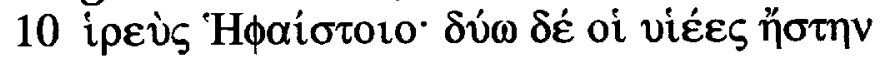

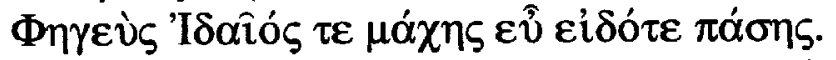

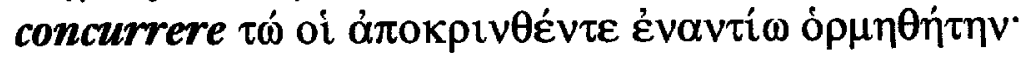

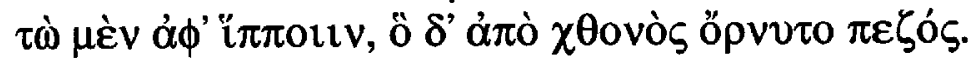

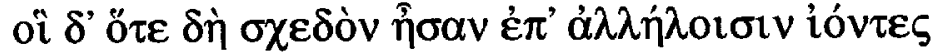

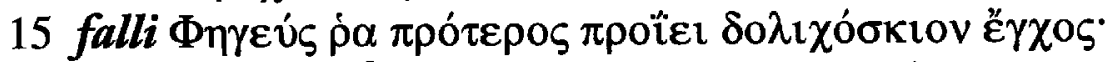

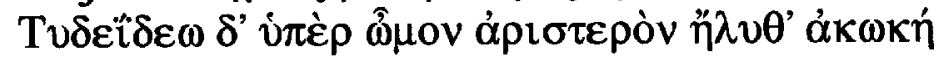

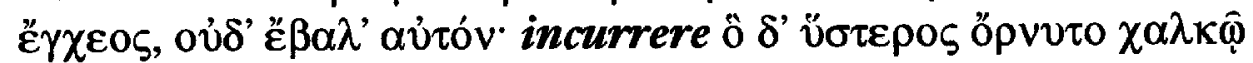

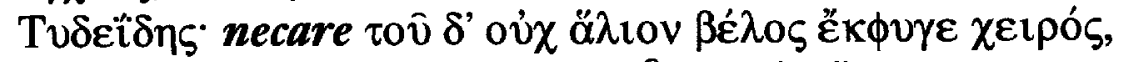

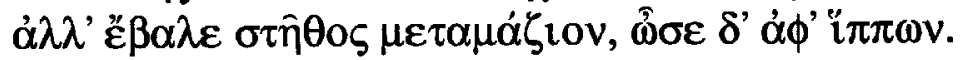

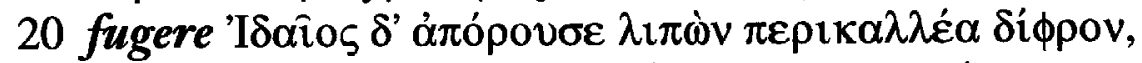

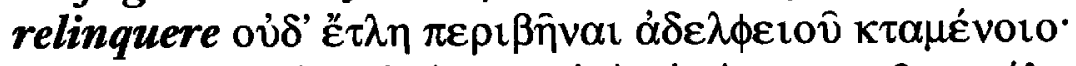

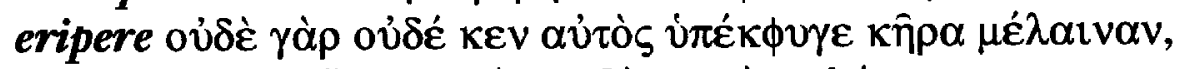

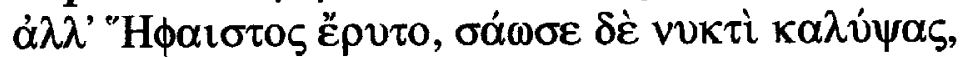

-dolere $\dot{\omega} \zeta \delta$ oi

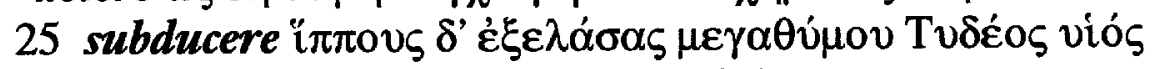

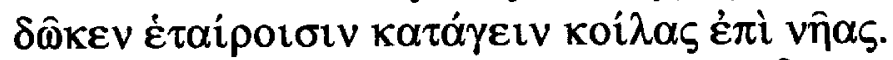

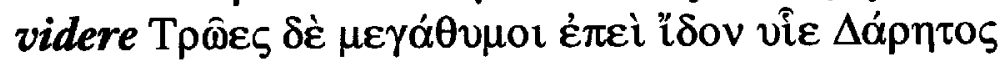

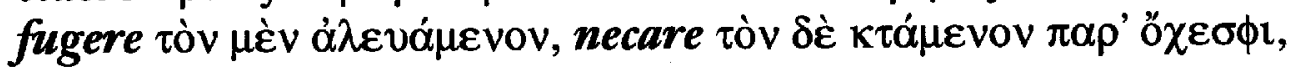

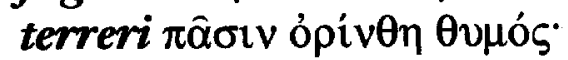

\section{Enteuxis}

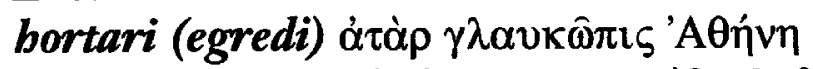

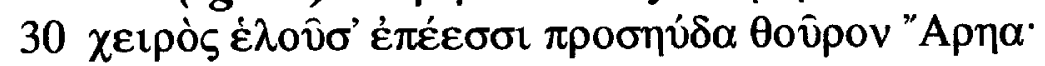

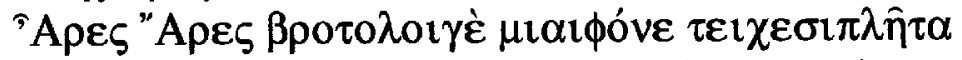

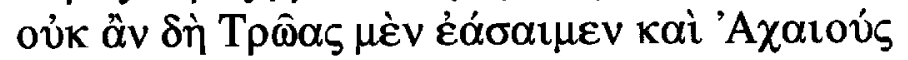

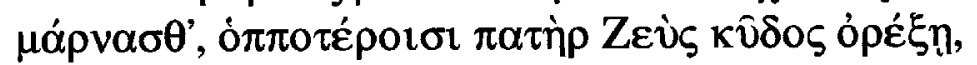

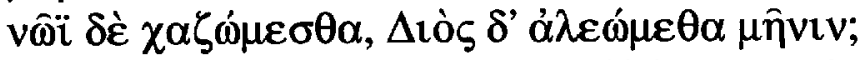

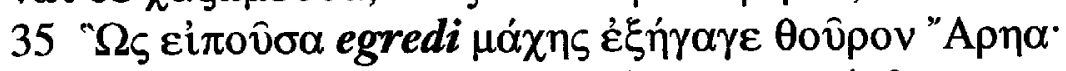

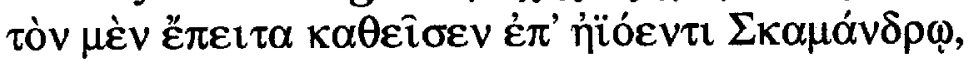

\section{Mache}

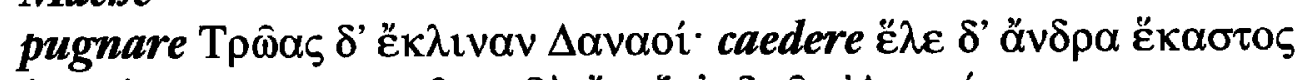

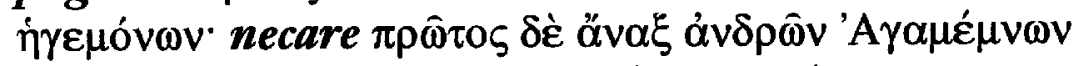

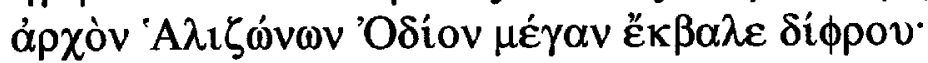

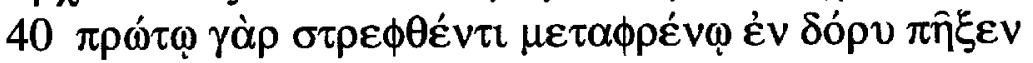

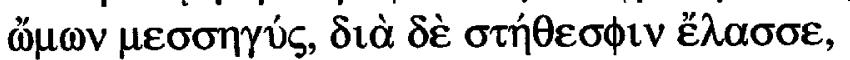

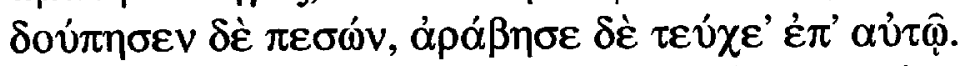

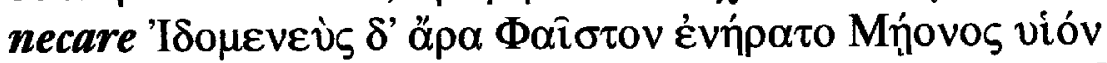

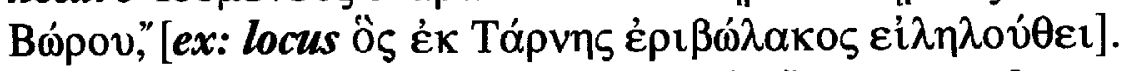

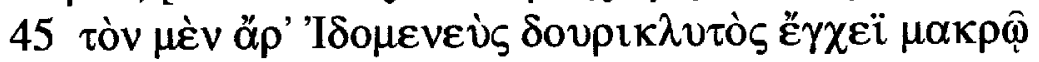




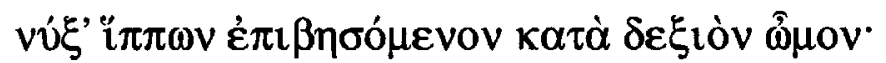

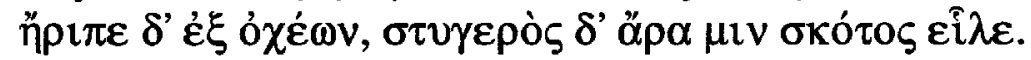

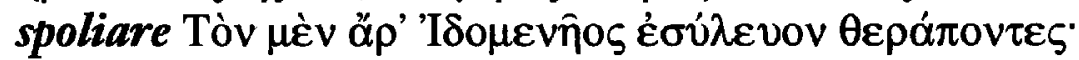

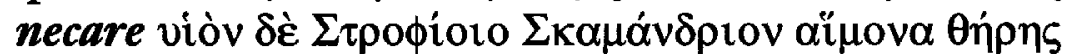

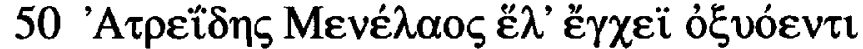

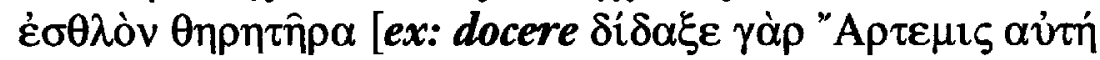

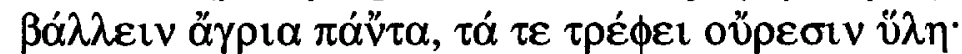

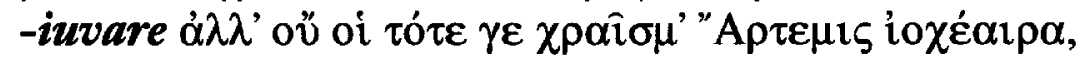

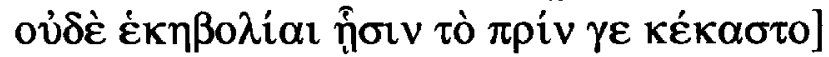

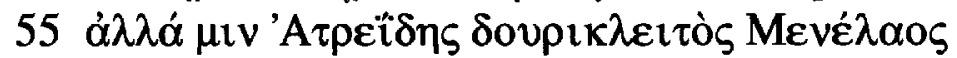

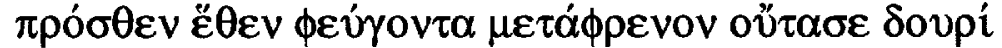

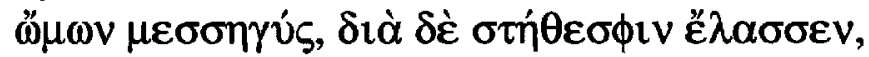

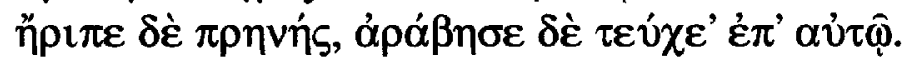

The motifs of E 1-200 have been analyzed by G. Kirk in his chapter about Typical motifs and themes, in the second volume of The Iliad: $A$ Commentary ${ }^{13}$. The main difference between our analysis (E 1-58) and the one of Kirk is that we identify the themes too, and that the definitions of the motifs are more generic and synthetic, because in this way we can obtain a more comprehensive and simple, and therefore more useful comparative system. For example, we don't identify as distinct motifs at 19 location of the wound, at 42 mode of dying, at 47 darkness/death envelops victim, but we consider these elements as variable components of the same motif necare, «killing an enemy».

In the second sample, we present the analysis of two Monomachiai or Duels, in which it is possible to compare the use of the motifs and their sequence, and to identify the thematic pattern ${ }^{14}$.

$\Upsilon$ 419-455 Duel between Hektor and Achilleus

\section{Monomachia}

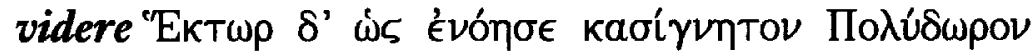

420 necare Ë

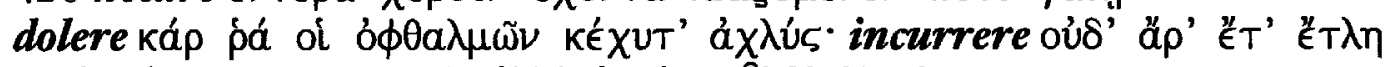

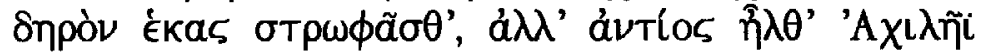

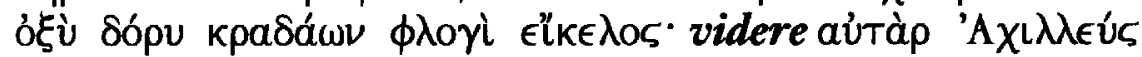

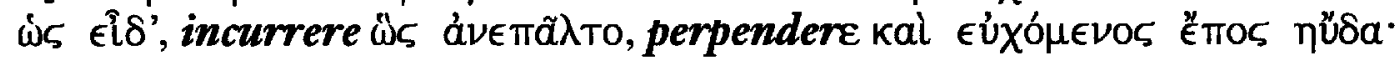

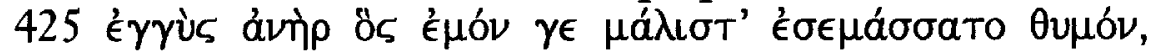

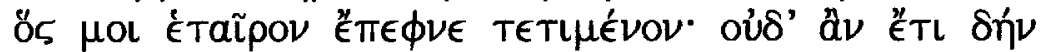

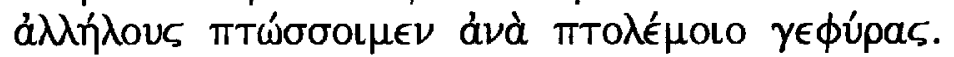

13. Kirk 1990, 15-27.

14. On the motifs and the thematic structure of the Monomacbiai, see Camerotto 2001. 


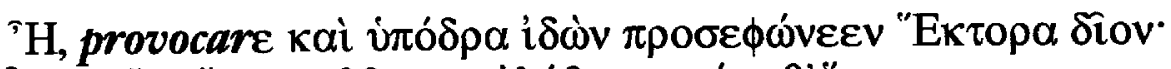

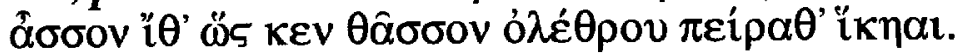

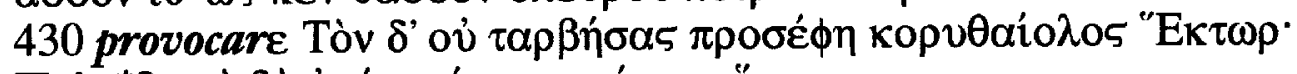

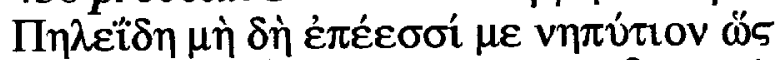

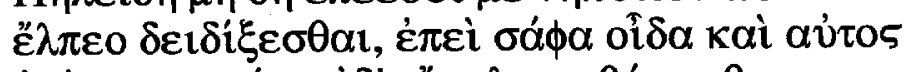

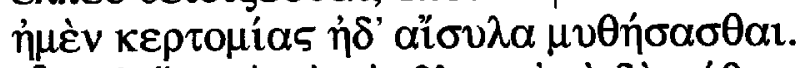

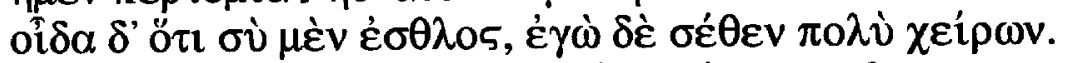

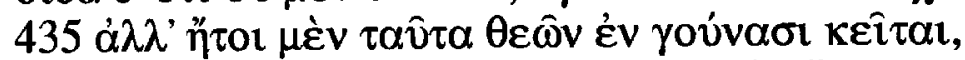

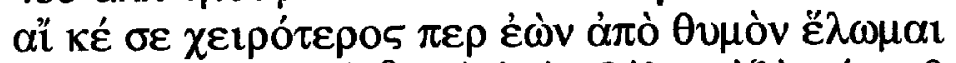

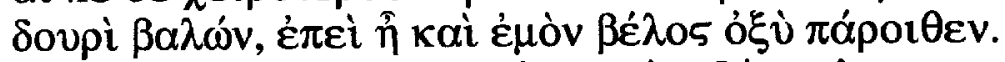

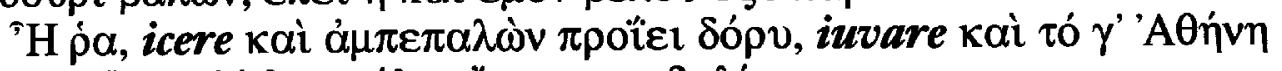

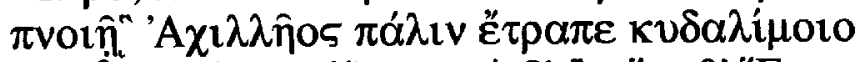

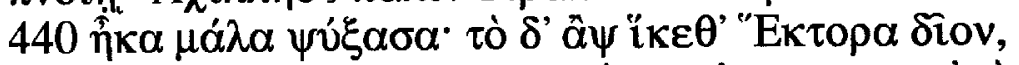

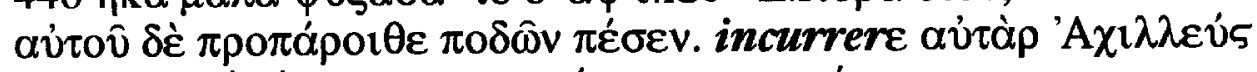

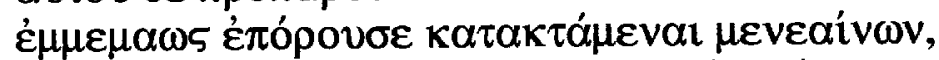

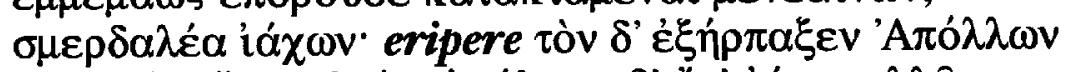

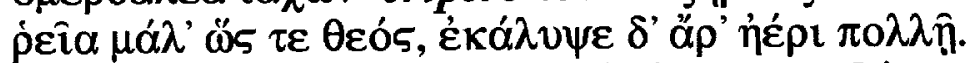

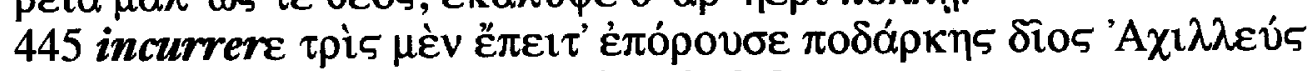

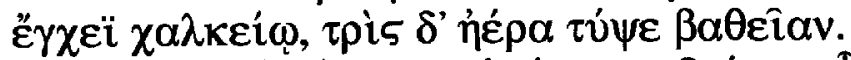

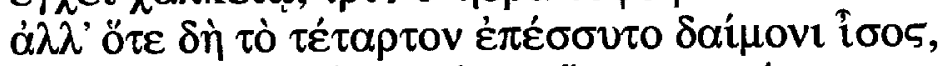

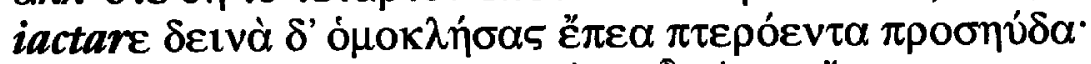

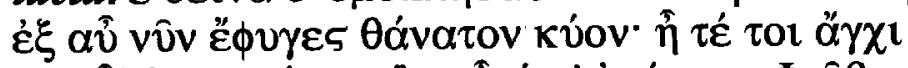

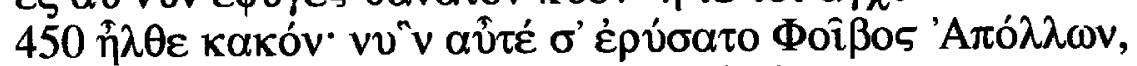

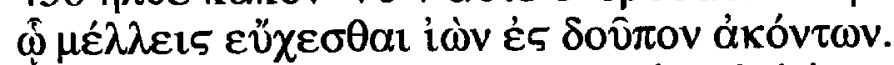

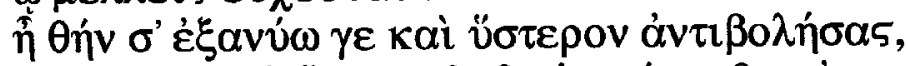

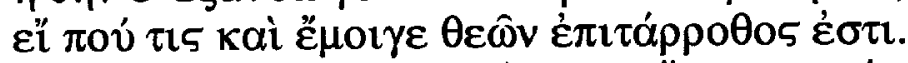

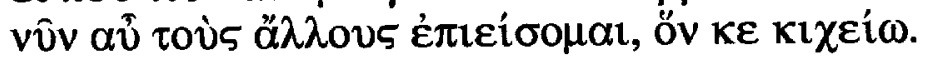

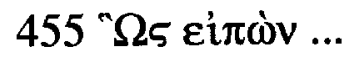

Ф 544-598 Duel between Agenor and Achilleus

\section{Monomacbia}

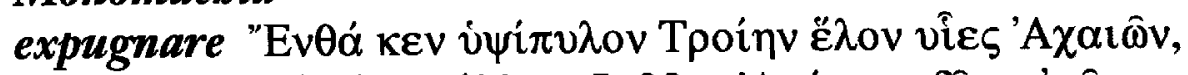
545 incitare $\varepsilon i$ i $\mu$ ' 'A

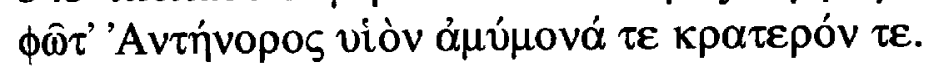

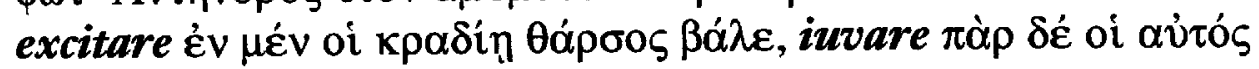

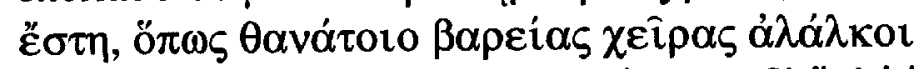

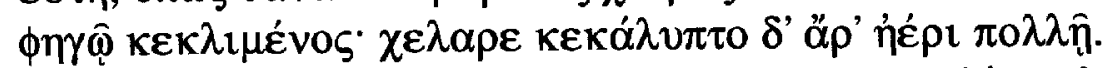

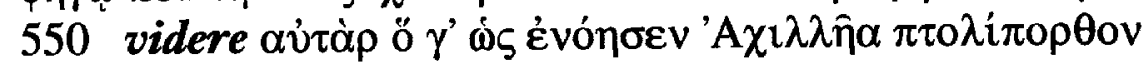

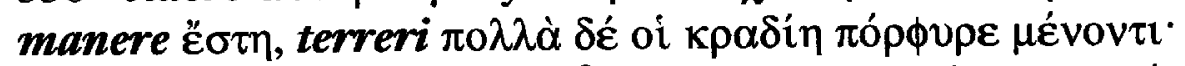

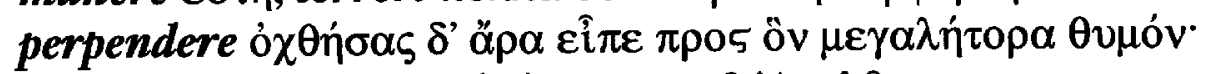

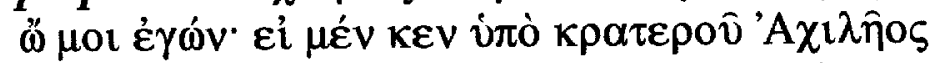

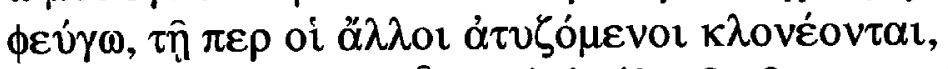

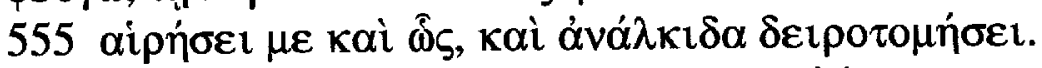

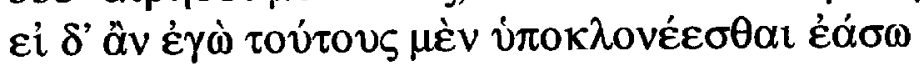




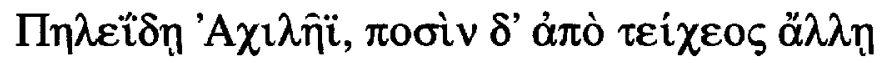

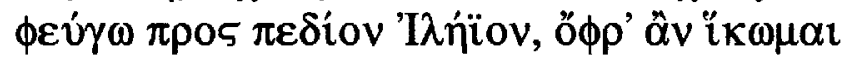

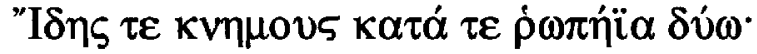

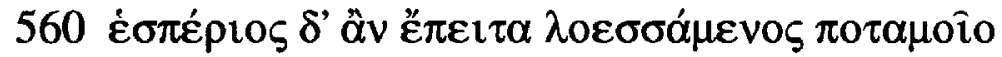

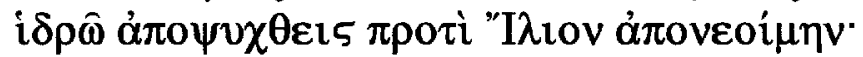

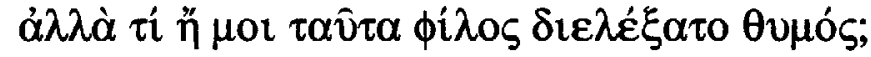

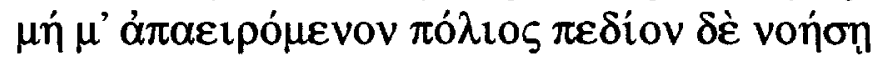

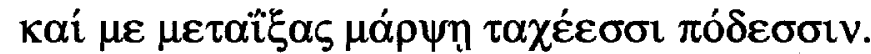

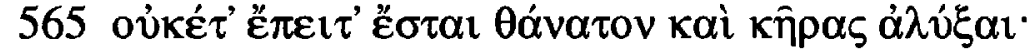

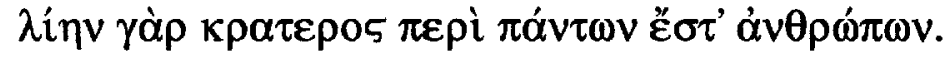

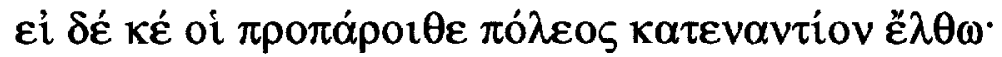

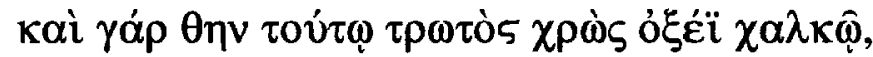

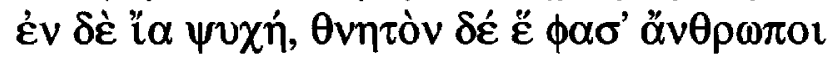

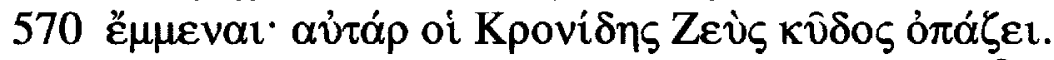

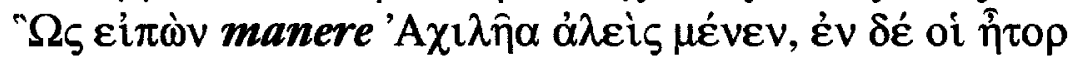

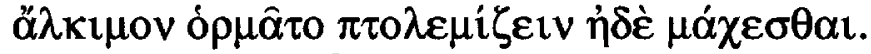

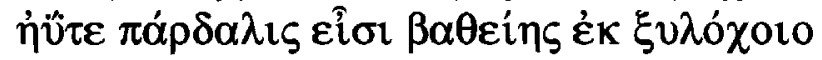

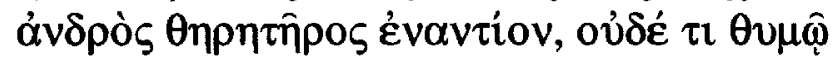

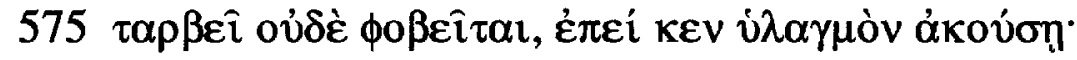

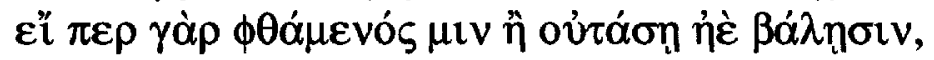

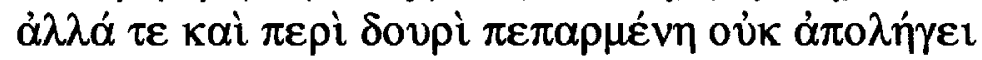

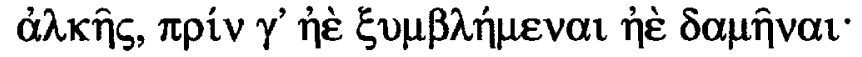

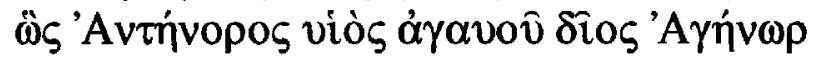

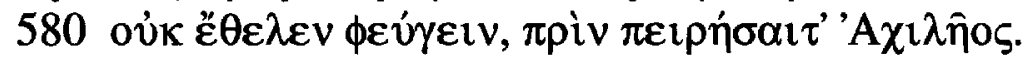

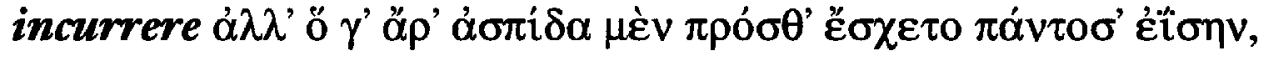

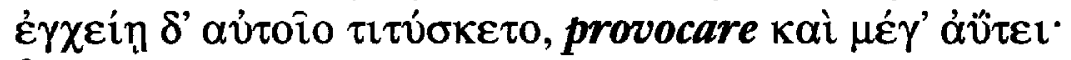

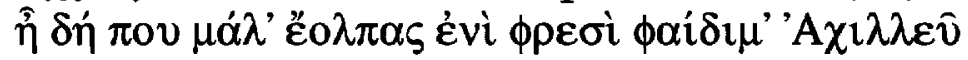

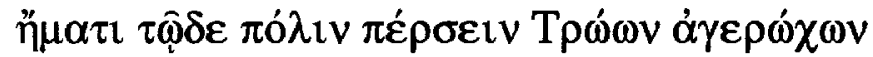

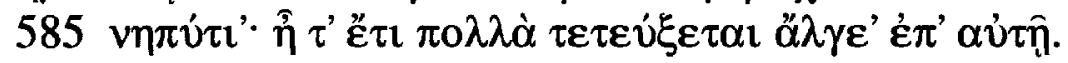

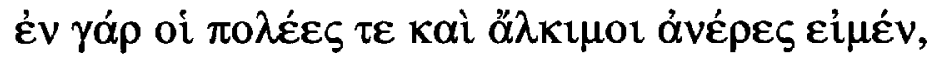

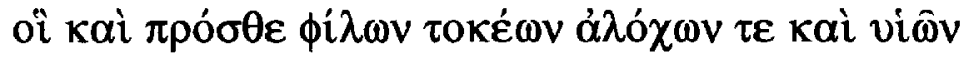

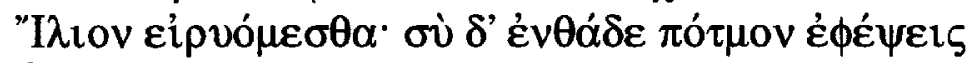

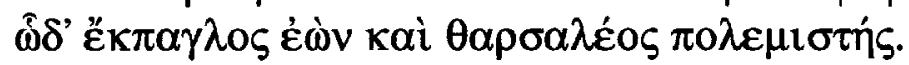

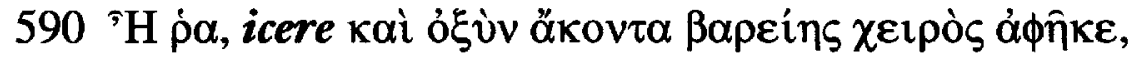

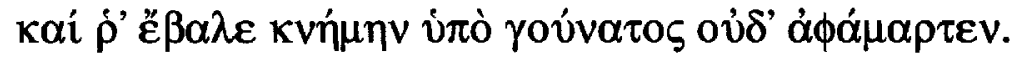

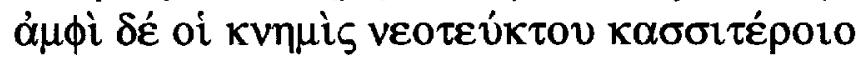

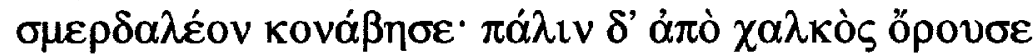

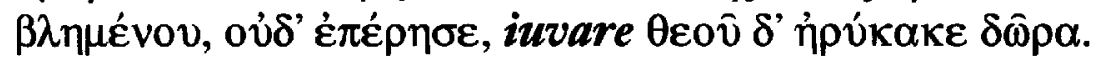

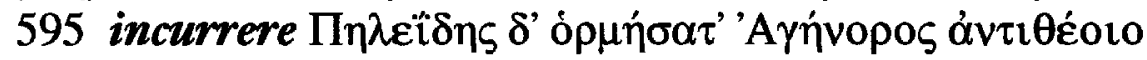

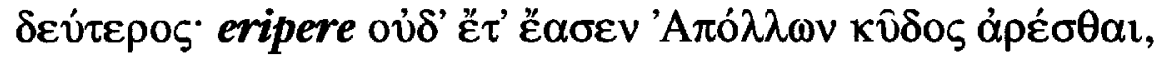

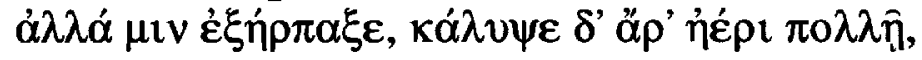

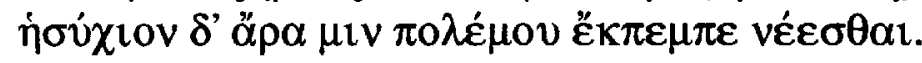




\section{References}

Arend, 1933, Die typischen Scenen bei Homer, Berlin 1933.

Camerotto A., «Aristeia. Azioni e tratti tematici dell'eroe in battaglia», AevAnt 14, 2001, 261-306.

Cantilena M., «Il cantore riprende», QU 55 (84), 1997, 141-154.

Edwards M.W., «Type-Scenes and Homeric Hospitality», TAPhA 105, 1975, 51-72.

—, «Convention and Individuality in Iliad $1 », H S C P b$ 84, 1980, 1-28.

-, «The conventions of a Homeric Funeral», in Studies in Honour T.B.L. Webster, ed. by J.H. Betts, J.T. Hooker, and J.-R. Green, Bristol 1986, 84-92.

- «Topos and Transformation in Homer», in Homer: Beyond Oral Poetry, ed. by J. M. Bremer, I. J. F. de Jong, and J. Kalff, Amsterdam 1987, 47-60.

-, «Homer and Oral Tradition: The Type-Scene», Oral Tradition 7, 1992, 284-330.

Fenik B., Typical Battle Scenes in the Iliad, Wiesbaden 1968.

-, «Stylization and Variety: Four Monologues in the Iliad», in Homer: Tradition and Invention, ed. by B. Fenik, Leiden 1978, 68-90.

de Jong I.J.F., Narrators and Focalizers: The Presentation of the Story in the Iliad, Amsterdam 1987.

Kirk G.S., The Iliad: A Commentary. Volume II: Books 5-8, Cambridge 1990.

Lord A.B., «Homer and Huso. II: Narrative Inconsistencies in Homer and Oral Poetry», TAPbA 69, 1938, 439-445.

-, «Composition by Theme in Homer and Southslavic Epos", TAPbA $82,1951,71-80$.

-, The Singer of Tales, Cambridge, Mass. 1960.

Morrison J.V., «Alternatives to the Epic Tradition: Homer's Challenges in the Iliad», TAPhA 122, 1992, 61-71

«Kerostasia, the Dictates of Fate, and the Will of Zeus in the Iliad», Aretbusa 30, 1997, 273-296.

Nagler M.N., Spontaneity and Tradition, Berkeley-Los Angeles 1974.

Parry M., «On Typical Scenes in Homer », CPh 31, 1936, 357-360 (= The Making of Homeric Verse. The Collected Papers of Milman Parry, ed. by A. Parry, Oxford 1971, 404-407).

Patzer H., Dichterische Kunst und poetisches Handwerk im bomerischen Epos, Wiesbaden 1972.

Pavese C.O.-F. Boschetti, A Complete Formular Analysis of the Homeric Poems, Amsterdam 2003. 